\title{
Ethnobiology for the Future: Linking Cultural and Ecological Diversity. Edited by Gary Paul Nabhan. 2016. Arizona University Press, Tucson. 309 pp.
}

\author{
John Robert White ${ }^{1 *}$ \\ ${ }^{1}$ Department of Anthropology, Tulane University, New Orleans, USA. \\ *jwhite30@tulane.edu
}

Received September 11, 2018

OPEN ӘACCESS

Accepted November 10, 2018

DOI 10.14237/ebl.9.2.2018.1399

Copyright (c) 2018 by the author(s) licensee Society of Ethnobiology. This is an open-access article distributed under the terms of the Creative Commons Attribution-NonCommercial 4.0 International Public License (https://creativecommons.org/licenses/by-nc/4.0), which permits non-commercial use, distribution, and reproduction in any medium, provided the original author and source are credited.

Ethnobiology for the Future: Linking Cultural and Ecological Diversity takes readers on a vibrant journey across the current state of ethnobiology and its diverse contributions to the world. Brimming with powerful case studies, overviews of many major contemporary issues in ethnobiology, and much food for thought in general, the evocative writing style of Nabhan and colleagues is sure to captivate readers from any background, academic or otherwise. Drawing upon insights collected from decades of diverse analytical perspectives, Nabhan and colleagues have assembled this collection of essays to increase the depth and breadth of ethnobiological research and to bolster our capacity to explore the ethnobiosphere. The circumstances of many young and aspiring ethnobiologists are addressed directly. Each of the book's 20 chapters asks us to imagine a different facet of the discipline, providing an enjoyably diverse yet cohesive reading experience with intelligent topical transitions. The book itself is divided into the three primary sections described below.

In the first section, Nabhan and colleagues explore major contemporary questions in the field of ethnobiology. Chapter 1 analyzes the current state of ethnobiology as a field of study, its lingering limitations, and strategies for improvement. Chapter 2 focuses on emerging disciplinary trajectories, particularly the blending of political ecology and ethnobiology. Chapter 3's discussion of the differences and similarities among Indigenous science, citizen science, and professional science is an especially important read, particularly for those of us working on biocultural diversity research and conservation. For example, Indigenous conceptualizations of plant domestication and diversification can potentiate multicultural conservation or participatory breeding efforts involving crop or crop wild relative diversity. Similarly vital to such efforts is the discussion of autobiology, or the "ethnobiology of us", which comprises Chapter 4, in which readers are encouraged to explore the ethnobiological terms and principles that guide their own lives and cultures. Next, the one-size-fits-all approach of certain diets (e.g., the modern Paleolithic diet) is critiqued in Chapter 5, which explores the medically meaningful variation between modern humans and our common ancestors and what this may mean for modern diets. The understudied ethnobiology of microorganisms (e.g., those in fermenting vats, vinegar mothers, human guts) is thoughtfully discussed in Chapter 6. Ethnophenology and climate change are examined in Chapter 7, providing thought-provoking examples of ethnophenological indicators (e.g., gooseberry bushes coming into their full leaves is a sign that it is time to start planting corn) that will likely spark many new research projects.

The second section discusses tools or methods which can help explore some of the types of major questions introduced in section one. This section begins with Chapter 8 detailing a case study of the Colorado Plateau ecoregion to better explore interactions between biological diversity, ethnolinguistic diversity, and multicultural conservation initiatives. Changes and continuities in desert oasis agrobiodiversity are investigated in Chapter 9, in part through the historical analysis of 
missionary archives. Chapter 10 details some important barriers to traditional ecological knowledge transmission, emphasizing the importance of placebased learning and hands-on activities. Chapters 11 and 12 explore effective conservation strategies targeting many place-based heritage foods and heirloom seeds and the importance of effective collaboration between their diverse actors. The multidisciplinary approach to the study of crop domestication, which is reviewed and expanded on in Chapter 13, exemplifies the hybrid vigor of thoughtful interdisciplinary project design. Specifically, Chapter 13 explores the origin of domesticated chili pepper (Capsicum annum in Mexico via biogeographic, archeological, paleolinguistic, and climatic perspectives. Finally, while ethnobiology has often been misconstrued as an exclusively historical science, Chapter 14 outlines the disciplines' true predictive power through a study of condor recovery and anthropogenic landscape modifications.

In the third section, ample room is left to an understudied yet crucial question, namely, how ethnobiologists can communicate more effectively with other scholars and society in general. Chapter 15 presents a particularly powerful story about a Seri sea turtle hunter, the collapse of a sea turtle population when local knowledge escaped local hands, and the collaborative conservation efforts seeking to improve human relations with these weeping creatures the Seri classify as a type of human. This chapter details the stunning extent of some traditional ecological knowledge and its importance to research and conservation projects (e.g., see the Seri science discussion on sea turtle biology, ecology, and the associated reactions from other scientists). Chapter 16 discusses "ghosts of evolution" (i.e., ecological anachronisms) through a discussion of the ethnozoological work of Paul Martin and the evolutionary and cultural forces that shape organisms and landscapes. In Chapter 17, Nabhan discusses the unique and immensely important Parque de la Papa, an in situ crop conservation effort among Quechua speakers in Peru, which any student of agrobiodiversity or conservation should familiarize themselves with (see also the excellent agrobiocultural conservation research and resources from the Native Seeds/ SEARCH initiative and web portal). Similar conservation projects are sorely needed in other hearths of crop domestication and centers of plant diversity (e.g., Amazonia). Aspiring community-based or in situ crop and crop wild relative conservation projects can learn much from these two highly effective initiatives. Chapter 18 explores how communications between many scientists, poets, novelists, and literary critics studying the environment have eroded over time, and what can be gained from bridging this current fissure. Readers will then find themselves transported into one whirlwind of a spice odyssey (Chapter 19), beginning in the Arabian deserts, where unique chemical ecologies and landscape modifications helped birth the global trade in aromatics some 3,000 years ago. This chapter's discussion of one of the most sought-after incenses in the world, frankincense (Boswellia sacra) of the hojar fusoos quality, known to its collectors simply as "milk" (buban in Arabic), will leave many mouths watering. This final section closes with Chapter 20, which discusses the ethnobiology of post-apocalyptic dystopias by engaging with major questions in translational science (e.g., how to express the values, benefits, and facts of a science to intraculturally and interculturally diverse audiences without "dumbing information down"). This chapter suggests some popular book genres (e.g., climate fiction) may provide help.

Building off the interrelated themes of its preceding chapters, the afterword of Ethnobiology for the Future expands upon its discussion of ongoing problems in the discipline and discusses strategies through which we may more effectively address them. This concluding section also contains a helpful collection of current academic programs in ethnobiology and a great overview of major names in the field's development, which many will appreciate. Like each of the prior chapters, every new reading of this section can result in new and insightful observations. In sum, Nabhan and colleagues have written another thoroughly enjoyable book, sure to be a key text in ethnobiological literature. 